
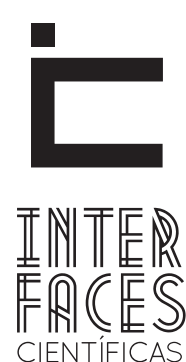

HUMANAS E SOCIAIS

ISSN IMPRESSO 2316-3348

E-ISSN 2316-3801

DOI - 10.17564/2316-3801.2017v6n1p21-32

\title{
PANORAMA DAS CONDIÇ̃̃ES FEMININAS NO AMAZONAS: DO PERÍODO COLONIAL AO SÉCULO XX
}

SCENE OF THE FEMININE CONDITIONS IN THE AMAZON: FROM THE COLONIAL PERIOD TO THE TWENTIETH CENTURY

PANORAMA DE LAS CONDICIONES DE LA MUJER EN EL AMAZONAS: PERÍODO COLONIAL HASTA EL SIGLO XX

Vívian Silva Lima Marangoni ${ }^{1}$

André Luiz Machado das Neves ${ }^{3}$

Gizelly de Carvalho Martins ${ }^{5}$
Glaucia Ribeiro Starling Diniz ${ }^{2}$

Munique Therense Costa de Morais Pontes ${ }^{4}$

\section{RESUMO}

0 presente artigo retrata um panorama das condições femininas no Amazonas do período colonial ao século XX, com a implantação da Zona Franca de Manaus. Inicia-se com uma análise do mito das índias "exóticas" e "dispostas" a satisfazer a lascívia do homem branco. Aborda-se a visão estruturada pelas representações da "mulher que não se dá com seringa”, da mulher de padrão europeu que serve para casar e da mulher pobre responsável pela existência da imoralidade. Após isso, segue análise sobre o período da Zona Franca de Manaus em que as mulheres vivenciaram o sexismo no mercado de trabalho industrial o que suscitou a organização de movimentos femininos no PIM. Essa análise permitiu compreender as variações nas condições femininas na Amazônia, fragmentos da história de mulheres amazonenses, sob o viés dos papéis de gênero relacionando com o pensamento de autoras feministas e registrar a contribuição das mulheres da região ao desenvolvimento e autonomia territorial.

\section{PALAVRAS-CHAVE}

Mulher. Gênero. Amazônia. Amazonas. Gênero na Amazônia. 


\section{ABSTRACT}

This article portrays a scene of female conditions in the Amazon from the colonial period to the 20th century with the establishment of the free zone of Manaus. It starts by an analysis of the myth of the "exotic" and "India willing" to satisfy the lasciviousness of the white man. It discuss the structured vision for representations of the "woman with syringe", the wife of European standard to marry and the poor woman responsible for the existence of immorality. After that, follow analysis of the period of the free zone of $\mathrm{Ma}$ naus, where women have experienced sexism in the industrial labour market that reveal the Organiza- tion of women's movements at the pole. This analysis allowed us to understand that variations in women's conditions in the Amazon, fragments of the story of Amazon women under the bias of gender roles relating to the idea of feminist authors, and register the contribution of women in the region to development and territorial autonomy.

\section{KEYWORDS}

Woman. Gender. Amazon. Amazonas. Gender in Amazon.

\section{RESUMEM}

Este artículo presenta un panorama de las condiciones en la Amazonia de la época colonial al siglo XX, con el establecimiento de la Zona Franca de Manaos. Comenzó con un análisis del mito de lo "exótico" y “India dispuesta" para satisfacer la lascivia del hombre blanco. Discute la visión estructurada de las representaciones de la "mujer que no se da con jeringa", la esposa del estándar europeo para casarse y la pobre mujer responsable de la existencia de la inmoralidad. Después de eso, seguir el análisis del período de la Zona Franca de Manaos, donde las mujeres han experimentado el sexismo en el mercado de trabajo industrial que revelan la organización de mujeres de movimientos en el poste. Este análisis nos permitidas entender que las variaciones en las condiciones de las mujeres en la Amazonia, fragmentos de la historia de las mujeres de Amazon bajo el sesgo de género, relativos a la idea de autoras feministas y registro de la contribución de las mujeres en la región para el desarrollo y la autonomía territorial.

\section{PALABRAS CLAVE}

Mujer. Género. Amazonas. Género en la Amazonia. 


\section{INTRODUÇÃO}

Neste artigo, resultado de pesquisa bibliográfica, pretende-se refletir sobre as condições femininas no Amazonas do período colonial até a implantação da Zona Franca de Manaus, no século XX. A expressão Condições Femininas recebeu definição na obra Condição Feminina: fator de risco para a Saúde Mental? da psicóloga Gláucia Diniz (1999) e se refere à subordinação das mulheres em relação aos homens que, ao longo da história, resultou no seu lugar secundário e desvalorizado na sociedade. Segundo a autora, a noção de mulher de "natureza frágil e misteriosa" foi, incontáveis vezes, utilizada para justificar o rígido controle sobre elas. Tendo seu corpo vigiado pela igreja e por alienistas; hoje seu algoz é também o capitalismo (DINIZ, 1999).

A vigilância e controle do corpo feminino podem ser identificados no exotismo e a fantasia que caracterizaram a Amazônia e seus habitantes. A mulher amazônica, muitas vezes, apareceu na história travestida de uma imagem que a desvaloriza, que a torna selvagem, sexualizada e primitiva. Índias, caboclas ${ }^{1}$, ribeirinhas, mulheres de áreas rurais e urbanas que ainda vivenciam, de diferentes formas, as consequências da hegemonia do pensamento do período colonial corrente que exaltou o masculino, o branco/europeu. Traços do pensamento colonial ultrapassaram o período áureo da borracha e a implantação da Zona Franca de Manaus, nas décadas 1960/1970 e permaneceram no século XXI, secundarizando duplamente a mulher amazônica, uma vez que, além de ser muIher, ainda é cabocla (TORRES, 2007; LIMA, 2009).

Neste artigo não se tem a pretensão de abarcar toda a complexidade do tema, nem de lhe dar-lhe definições e conclusões. Pensa-se que, a partir da perspectiva só-

1 A cultura cabocla não é simplesmente restos de sociedades indígenas, naturalizada, independente; é um projeto incompleto de criação de uma cultura brasileira que rompeu com seus antecedentes indígenas, negros, europeus (ADAMS; MURRIETA; NEVES, 2008). 0 caboclo não é artefato do Novo Mundo, mas artefato do empreendimento de povoação e colonização da Amazônia que vem se ajustando e se reinventando com certa flexibilidade em períodos de boom e estagnação no seu processo de desenvolvimento (HARRIS, 2008; NUGENT, 2008). cio-histórica, é possível realizar um panorama dessas condições nos períodos colonial, áureo da borracha e de implantação da Zona Franca de Manaus, com vistas a entender as condições femininas em diferentes momentos sociopolíticos e suas implicações na construção identitária das mulheres amazonenses.

\section{CONDIÇÕES FEMININAS NA AMAZÔNIA}

\subsection{PERÍODO COLONIAL: DO MITO DAS ÍNDIAS "EXÓTICAS" E "DISPOSTAS" A SATISFAZER A LASCÍVIA DO HOMEM BRANCO AO POVOAMENTO DA AMAZÔNIA}

No período pré-colonial, relatos de aventureiros, naturalistas e historiadores apontam para uma participação ativa das mulheres na economia e nas decisões políticas das tribos nativas. As mudanças nesse âmbito estão significativamente relacionadas ao processo civilizatório que escamoteou o papel e a participação feminina. Os traços da influência da cultura sexista e etnocêntrica dos colonizadores tornou a mulher invisível e desvalorizada, podendo ser este um dos maiores fatores geradores da invisibilidade e do preconceito contra as mulheres amazônicas (TORRES, 2007).

A cultura indígena também contribuiu para a dominação masculina no período colonial, mas não se pode afirmar que nas sociedades indígenas as mulheres sejam submissas aos homens, pois em algumas tribos é possivel encontrar mulheres chefes. 0 que existe é uma nítida divisão sexual do trabalho. Em geral, é responsabilidade das indígenas o trabalho doméstico e o cuidado com os filhos, mas não se vê nelas a passividade feminina nos moldes do patriarcalismo (COSTA, 2000; TORRES, 2005).

Pode-se destacar que, no mundo ocidental, a mulher sempre foi vista de forma ameaçadora. 0 poder patriarcal se apropriou do seu corpo por objetivos econômicos. A igreja colocou-lhe cintos de castidade e embutiu nela toda a culpa pelo paraíso perdido, ou seja, o pecado era ela própria. Os renascentistas acusaram-na de desviar os homens do caminho da razão, uma vez que a paixão os levaria à insanidade. 
$\mathrm{Na}$ Amazônia, esse controle foi ainda mais cruel. $\mathrm{Na}$ obra de Torres (2005) observa-se que as políticas implementadas para povoar e ocupar o território amazônico, assim como para impedir possíveis invasões estrangeiras, usaram o corpo das nativas como um instrumento de dominação - delas e do território. Enquanto no Ocidente se exigia das mulheres um comportamento casto e virginal, por motivos políticos e econômicos, na Amazônia, a liberdade sexual, principalmente entre colonizadores e indígenas, foi estimulada.

Tal motivação, contudo, não se deu de forma aleatória. Pensa-se ter havido uma espécie de organização da permissividade sexual, de forma que ela tenha se constituído não como liberdade sexual em si, mas como norma. Seguindo a lógica foucaultiana (FOUCAULT, 2015), é possível pensar que o modo cultural com que os indígenas vivenciavam a sexualidade foi um dispositivo para a construção da imagem da índia lasciva e parideira com a finalidade de recrutar homens brancos para ocupar e povoar a Amazônia.

Assim, mediante o uso desta imagem de índia o governo lusitano implantou, na Amazônia, um verdadeiro comércio sexual com claros fins militares, políticos e religiosos. Os missionários, coadunados com esses objetivos, ora condenavam a naturalidade sexual dos nativos, ora exerciam a permissividade, servindo aos processos de colonização e dominação territorial. Sobre isso, destaca-se o trecho abaixo:

[...] O fato é que o comportamento da Igreja era marcado pela plasticidade, fechando os olhos a princípios da doutrina frente a uma atitude de quase servilismo ao poder Real com o qual se mantinha atrelada. E o concubinato de brancos e índias proliferou na colônia livremente, absorvendo inclusive os clérigos. (COSTA, 2000, p. 59).

Um dos momentos de maior uso desta norma sexual pode ser identificado em meados do século XVIII. A partir de 1750, no Governo de D. José I, a Coroa lusitana, regida pelo então Primeiro-Ministro Sebastião José de Carvalho e Melo, futuro Marquês de Pombal, tomou uma série de medidas para reorganização administrativa do império. Entre as medidas estavam o desenvolvimento de uma indústria manufatureira no reino, a ex- ploração sistemática dos recursos naturais e humanos das colônias e uma série de ordens que norteavam as relações entre os nativos e os colonos, contidas num documento real denominado Diretório Pombalino.

o Diretório Pombalino consistiu em um conjunto de medidas indigenistas tomadas por Marquês de Pombal. Entre elas, a criação da Companhia Geral do Grão-Pará e Maranhão, para a exploração dos produtos da Amazônia, extinção do poder dos missionários, abolição da escravidão indígena, povoação e urbanização da colônia (GUZMÁN, 2008). Na Amazônia, o Diretório Pombalino foi executado pelo governador do Estado do Grão-Pará e Maranhão, meio-irmão de Marquês de Pombal.

O Diretório supracitado é um documento importante na compreensão da Condição Feminina das mulheres da Amazônia porque, segundo Guzmán (2008, p. 74), este é o contexto de criação e promoção de políticas de estimulação ao casamento entre portugueses e índias de diversas etnias. O Diretório proibia a discriminação taxativa para os homens que se casassem com as nativas e também proibia o uso do termo caboclo, pois, segundo o alvará régio, o termo cabouclo era injurioso e ofensivo e dava àqueles que se fixassem em vilas e povoados da colônia "atenção especial" da Coroa, honrarias, isenção de impostos e bens (GUZMÁN, 2008; RAYMUNDO, 2006).

Identifica-se, pois, que a política de Pombal instalou um comércio sexual no território amazonense. Para Torres (2005) o comércio sexual foi uma estratégia sexista para povoar a Amazônia, com base em práticas sexuais induzidas pelo poder lusitano e discretamente permitidas pela Igreja. Essas práticas atendiam tanto ao interesse da Coroa de ocupação, quanto o da Igreja de disseminar o catolicismo. Para que conseguissem sobreviver na Amazônia - material e politicamente - participar do comércio sexual foi compulsório para muitas das famílias indígenas. Em troca de alimentos, bebidas e, sobretudo, para fugir da exclusão social, pais e maridos entregaram suas filhas e esposas, respectivamente, para homens brancos que visitavam povoados indígenas em função de algum negócio. 
Com base nesse contexto, nosso primeiro argumento é que o "mito de que as índias eram mulheres exóticas e dispostas a satisfazer a lascívia do homem branco, quando, na verdade, o objetivo era povoar a Amazônia" (TORRES, 2005, p. 27) legitimou a condição feminina da mulher amazonense. Esse momento histórico foi caracterizado pelo uso e mercantilização do corpo das nativas por questões políticas, econômicas e para garantir a soberania das terras ocupadas.

\subsection{PERÍODO DA BORRACHA: A “NULHER BÃO SE DÁ COM SERINGA", O CASAMENTO ENQUANTO STATUSSOCIAL, A MULHER POBRE RESPONSÁVEL PELA “IMORALIDADE” E AS PÁLIDAS COCOTTES.}

Durante a colonização e até aproximadamente a primeira década do século XX, a economia da Amazônia era essencialmente extrativista. A busca pelo Eldorado na "terra das Amazonas" atraiu levas de imigrantes em muitos momentos da história. A ocupação que se iniciou nos séculos XVIII e XIX com a busca de especiarias - como pimenta, cravo, canela, cacau, baunilha etc. ${ }^{2}$ - teve um enorme acréscimo no fim do século XIX com o período áureo da borracha.

A exploração e a exportação da borracha trouxeram grandes mudanças sociais e econômicas para a Amazônia. 0 boom da borracha que aconteceu entre os anos de 1898 e 1912, tornou Manaus, capital do Amazonas, uma cidade com ares cosmopolita e grandes obras mudaram a fisionomia da cidade, até então com características provincianas.

Juntamente com o Pará, o Amazonas tinha uma das maiores rendas per capitas do hemisfério sul. Entretanto a riqueza obtida foi direcionada para consumo e obras majestosas e não para o desenvolvimento econômico (OLIVEIRA, 2006). Os benefícios advindos do "ouro branco" ficaram concentrados nas mãos de poucos. Os grandes seringais pertenciam à famílias tradicionais de Manaus e Belém, mas o sangue de indígenas destribalizados e de milhares de imigrantes foi a seiva que financiou

2 Produtos que ficaram conhecidos como drogas do sertão. os caprichos e extravagâncias da elite dessas duas cidades (OLIVEIRA, 2006; ORUM, 2001).

A mão de obra dos seringais era formada majoritariamente por homens. Solteiros, em sua maioria nordestinos, deixaram suas famílias na esperança de dias melhores e na expectativa de retornar ou trazê-las para junto de si. Contudo, normas de proibição foram adotadas para manter mulheres e filhos longe dos seringueiros. 0 regime agroexportador promovia a vinda de homens solteiros com o pretexto de que "Seringa não se dava com mulher" (BENCHIMOL apud TORRES, 2005, p. 22). As péssimas condições de trabalho a que os seringueiros eram expostos beiravam a escravidão e, sem possibilidades financeiras, muitos deles nunca reencontrariam suas famílias. Era preciso garantir que a elevada produção gomífera não fosse prejudicada por questões de ordem pessoal dos seringueiros.

A ausência de mulheres nos seringais representa uma rígida divisão sexual do trabalho. Torres (2005, p. 22) considera a exclusão da mulher nos seringais como outra forma de política sexista:

\footnotetext{
Enquanto que, no período da política pombalina, as mulheres foram requisitadas para participar da política de expansão física do território amazônico, dando visibilidade à imagem da mulher parideira; no período da economia da borracha, a mulher foi preterida nos seringais amazônicos.
}

A ideia da Amazônia como inferno verde inibia a chegada de mulheres de outras regiões do país. As indígenas eram proibidas de se relacionar com forasteiros, ao passo que aos seringueiros transgressores a infração poderia colocar em risco a própria vida (COSTA, 2000). As poucas mulheres brancas e mestiças existentes viviam em pequenos núcleos urbanos, porém eram as principais vítimas das diversas epidemias que chegavam com as embarcações. Assim, fica claro que a Amazônia, nesse período, era um terreno extremamente hostil para as mulheres.

As exceções eram as mulheres europeias que vinham ao Brasil para trabalhar em cabarés ou para conseguir um bom casamento com um barão da borracha. O luxo e riqueza ostentados pelas elites da 
borracha despertaram o interesse desse grupo de imigrantes. Orum (2001) aponta que enquanto nos seringais, a vida era árdua e solitária, nas capitais, a elite ostentava o luxo e o requinte importados da Europa.

Paris foi escolhida com a principal rota de turismo para os ilustres comerciantes da borracha e a cultura francesa era copiada, no vestuário, na arte, na etiqueta e, também, na prostituição. Na ocasião, chegaram a Manaus e a Belém, levas de europeias, conhecidas como polacas para trabalhar nos cabarés e teatros da região. A vida noturna era movimentada e as pálidas cocottes atraíam homens solteiros e casados. As prostitutas nativas foram desvalorizadas, ao passo que desfilar na companhia de uma mulher branca, estrangeira, bem vestida e penteada, representava excelente status econômico:

A tradicional ausência de sucesso das amazonenses, além de a maior parte dos habitantes terem traços regionais garantiu às europeias, às imigrantes luso-brasileiras e a uma pequena porcentagem de mulheres brancas na região uma espécie de prêmio pela cor. (...) As mulheres de cor - mulatas, caboclas, cafuzas, pretas - eram adequadas para rebolar, mas as mais graciosas e as que detinham a atenção eram as brancas, essas mulheres eram o topo da realização sócio-pessoal. (ORUM, 2001, s/p).

Parece que a importação da cultura europeia estigmatizou as formas de vida que existiam na Amazônia durante o boom da borracha. Ser amazônico era ser primitivo. Era preciso ser europeu para que se alcançasse a modernidade; ser branco/a para ser bonito/a. A citação acima demonstra que, se por um lado pôde-se identificar o prestígio e o valor que a sociedade da época atribuiu às cocottes, por outro, as mulheres da Amazônia foram secundarizadas pelo tom da sua pele, sua origem, sua cor. 0 maniqueísmo renascentista voltou a condenar indígenas e caboclos, e o uso estratégico da imagem da mulher indígena, amplamente realizado no período colonial, parece ter perdido a força de convencimento.

Embora os grandes navios a vapor tivessem trazido riqueza e luxúria para a linha do Equador, o prazer e a diversão só eram permitidos aos homens. Para as cortesãs e cocottes, a prostituição não era um exercício da sexualidade, mas significava uma forma de sobrevivência. Como um "ganha pão", o meretrício nas capitais da borracha foi tolerado, mas às prostitutas eram direcionadas todas as formas de punição e práticas coercitivas. No período em que, nas metrópoles do mundo inteiro, a cultura burguesa era exaltada e o casamento e o amor romântico dos folhetins eram altamente valorizados, as mulheres do meretrício foram culpabilizadas pela disseminação de doenças venéreas (SANTOS, 2007). Em Manaus e Belém não foi diferente.

Assim como a moda e os costumes, valores europeus foram importados para a Amazônia. O casamento passou a representar para as mulheres amazônicas status social, sobretudo para aquelas de famílias abastadas. Jovens de posses eram enviadas ao Rio de Janeiro e, à Europa, para se tornarem damas. Além de concluir os estudos, deviam aprender costumes modernos e civilizados que as ajudariam a conseguir um vantajoso casamento. Para as moças de classe média o casamento também era referência, entretanto o pouco patrimônio da família tornava os compromissos menos rígidos. Sem posses ou negócios para manter e assegurar elas tinham mais liberdade que as jovens ricas para escolher noivos e até para dispensá-los.

Nas classes populares, casamentos civis e religiosos, pelo alto custo, eram mais raros. Entre as camadas mais humildes, ou seja, entre a maioria da população, predominava o concubinato. A formalização nos arranjos e términos de relacionamentos amorosos e sexuais - com coabitação, inclusive - embora fosse desejada como o ideal, para homens e mulheres pobres era incomum. Quanto mais pobres fossem as famílias, mais liberdade e flexibilidade nos arranjos maritais, as muIheres dispunham. Por que isso acontecia? Cristina Cancela (2008, p. 313) apontou algumas explicações:

Entre os motivos que ajudam a pensar a presença dessa prática no universo desses casais, podemos amealhar as adversidades e limites materiais vividos por esses grupos; a ausência ou inexpressividade de bens patrimoniais; a instabilidade do trabalho e da moradia; a maior autonomia da mulher pobre e trabalhadora em relação aos homens, permitindo-lhe a autossustenta- 
ção e, com isso, uma suposta independência e a dificuldade de o homem manter seu papel socialmente construído de provedor.

Às mulheres ricas, brancas, em geral, descendentes de famílias colonizadoras era exigido um comportamento com raízes patriarcais e cristãs. Era elegante e moderno copiar valores familiares europeus. Mulheres pobres, em geral caboclas e mestiças, gozavam de uma maior liberdade e autonomia, tanto na relação com o trabalho, quanto na escolha de seus parceiros - característica bastante comum na cultura indígena. Logo, entende-se que a prostituição, o concubinato e a independência financeira das mulheres, apesar de ser uma realidade no período áureo da borracha, eram apenas tolerados, o que, segundo Cancela (2008), não é sinônimo de aceitação massiva das práticas.

Com o declínio da borracha, a partir de 1910, a economia de Manaus entrou em colapso, iniciando os "anos de escuridão". Ostentação, cafés e boulevards perderam espaço em função da queda nas finanças públicas, falência e desemprego. Os cinquenta anos seguintes são comumente descritos como "período da escuridão", momento em que o "glamour"de Manaus foi substituído pela crise econômica ${ }^{3}$.

Depois dos "anos de escuridão", foi com o discurso salvacionista de desenvolver e povoar a Amazônia Ocidental, que na década de 1950 a Zona Franca de Manaus (ZFM) foi concebida. Era preciso levar modernidade às pobres e primitivas populações caboclas e isso só seria possível por meio da industrialização. Pensa-se ser incontestável a importância do Projeto ZFM para o desenvolvimento da cidade, entretanto, a visão colonialista dos dirigentes dessas empresas promoveu no Pólo Industrial de Manaus (PIM) uma política preconceituosa e sexista que permanece em vigor até os dias atuais (LIMA, 2009).

$3 \mathrm{Na}$ atualidade este entendimento é considerado uma falácia etnocêntrica e preconceituosa, pois colocou em destaque uma suposta incompetência da população local para sustentar a economia, como se extrair látex fosse a única habilidade dos/as caboclos/as (NUGENT, 2008; TORRES, 2005).

\subsection{CONDIÇÕES FEMININAS NO POLO INDUSTRIAL DE MANAUS (PIM): SEXISMO E A CONSTITUICX̃̃O DE ATIVISMO POLÍTICO FEMININO}

Manaus é a única cidade no Amazonas com mais mulheres do que homens. São 879,7 mil homens $(48,82 \%)$ e 922,2 mil mulheres $(51,18 \%)$, diferença de 42,5 mil (IBGE, 2011). No PIM elas representam $55 \%$ da força de trabalho, absorvidas, em sua grande maioria por empresas produtoras de eletrônicos e componentes (IBGE, 2011).

A maioria dessas mulheres ocupa cargos de menor nível hierárquico - e de menores salários - como os de montadora, operadora de produção e calibradora. Em geral, elas são alocadas em setores onde é exigido ritmo acelerado, concentração, tensão, habilidade manual, acuidade visual e, sobretudo, paciência, dado o caráter repetitivo das tarefas (COSTA, 2000; IBGE, 2010; LIMA, 2009).

Os processos de seleção são mais rigorosos para as mulheres. Pela natureza dos trabalhos, que envolvem grande desgaste físico e psíquico, as empresas de eletroeletrônicos dão preferência à contratação de mulheres jovens. De preferência, elas devem ter idade de até 25 anos, ser solteiras, de preferência sem filhos, com boa aparência, altura e peso compatíveis, braços longos, mãos delicadas, ensino médio completo e sem experiência profissional anterior. Além desses pré-requisitos, a indicação de alguém influente é relevante para as candidatas.

As empresas dão prioridade para mulheres "tranquilas", "otimistas", "receptivas", com "comportamento discreto" e que tenham "hábitos adequados de higiene". Até a primeira década do ano 2000 , teste de gravidez fazia parte de uma lista de exame médicos a que as candidatas eram submetidas (SPINDEL, 1987; COSTA, 2000; BARBOSA, 2007). Resultados positivos eram desfavoráveis para a contratação o que implicava, na maioria das vezes, a desclassificação das candidatas.

Alguns dos critérios exigidos durante o processo de seleção deixam nítido o viés sexista. Mediante pressuposto de pouca resistência física, as mulheres ocupam cargos considerados mais fáceis e mais 
leves. Esse tipo de classificação, além de expressar uma lógica patriarcal, desvaloriza as atividades desempenhadas por mulheres, contribuindo para a manutenção de menores salários e piores condições de trabalho. Ademais, serviços que historicamente são atribuídos às mulheres no espaço doméstico, fazem com que, desde cedo, elas tenham uma maior habilidade em organizar o tempo. A facilidade em desempenhar atividades múltiplas e delicadas (cozinhar, costurar, cuidar de crianças e idosos etc.) que exige paciência e disciplina converte-se no espaço fabril, em maior lucro e produtividade, atendendo à lógica capitalista (COSTA, 2000).

Os homens são, em geral, contratados para cargos que exigem força física, ou seja, cargos técnicos e de manutenção. Assim, desempenham atividades "mais difíceis e complexas". Os setores onde predominam homens remuneram melhor, ao passo que aqueles ocupados apenas por mulheres têm os menores vencimentos. Cargos em que o sexo é indiferente não apresentam discrepâncias salariais. Nos cargos de maior nível hierárquico, as mulheres são minoria, elas são contratadas apenas para chefias menores. Em cargos de supervisão e gerência, os homens são maioria.

As empresas do PIM que, em geral, são filiais, com matrizes no sul do Brasil ou em outros países, têm critérios distintos para a contratação de chefias. Para coordenar grupos e assumir gerência, as empresas ainda contratam a mão de obra local, entretanto, para cargos mais altos, de diretoria e presidência, a quase totalidade é composta por funcionários da matriz ou estrangeiros (COSTA, 2000).

Seleção mais rigorosa, atividades exaustivas e desvalorizadas, salários inferiores e menores possibilidades de promoção para as mulheres, seriam informações suficientes para afirmar a existência de uma política sexista no PIM. Entretanto, estudos realizados em diferentes momentos (SPINDEL, 1987; COSTA, 2000; TORRES, 2005; BARBOSA, 2007; LIMA, 2009) apontam a existência de um rígido controle sobre o corpo e o comportamento das mulheres trabalhadoras do PIM, trazendo à tona estigmas seculares sobre a moral das amazônidas. 0 domínio sobre o corpo feminino, já aparecia durante a seleção: "boa aparência”, teste de gravidez e "comportamento discreto" colocam em evidência como o uso do corpo e a sexualidade podem interferir na contratação das candidatas.

Nas décadas de 1980/1990, a distribuição de pílulas anticoncepcionais às mulheres e o financiamento de cirurgias de laqueadura eram promovidas por empresas do PIM. Nessa mesma época, a exigência de um atestado de laqueadura para a contratação e exames realizados pelas líderes de linha, nos genitais e nos absorventes das operárias, foram práticas comuns de controle sobre a vida sexual e reprodutiva das operárias. 0 medo de demissão e de retaliação induziu - e induz até hoje - muitas trabalhadoras do PIM a realizarem abortos clandestinos, muitas vezes, nos banheiros das próprias fábricas. Além disso, foi proibido às mulheres, o uso de decotes e minissaias, como tentativa de moralizar o ambiente de trabalho (TORRES, 2005).

Casos amorosos, assédios sexuais e até estupros acontecem com bastante frequência entre chefes e operárias. Na década de 1980, algumas indústrias chegaram a proibir ligações amorosas e sexuais entre operárias e chefes de qualquer nível. Embora, atualmente não exista uma política explícita e formal sobre essa prática, atitudes vexatórias que desqualificam a moral das mulheres: "ela tem caso com o chefe porque é fácil”, colocam-nas em um lugar de responsabilidade pela conservação da moral. Dessa forma, aceitando ou não as investidas dos chefes elas estão vulneráveis às retaliações que partem tanto das chefias, quanto dos/das colegas de trabalho (LIMA, 2009).

A falta de informação, o medo de demissão e a possibilidade de obter vantagens salariais ou promoções levam algumas delas a aceitarem o assédio sexual como uma das atribuições dos cargos que ocupam. Muitas vezes, são os próprios chefes, atores do assédio que ridicularizam as operárias, maculando sua imagem. Fica perceptível assim que, independente da decisão que tomam sobre se envolver ou não com um colega ou chefe de trabalho, são elas que estão sendo vigiadas. Seu corpo está sendo constantemente usado e controlado de acordo com os interesses masculinos. 
Além do assédio sexual, a política sexista do PIM contra as trabalhadoras é também refletida em práticas menos visíveis. Torres (2005) afirma que uma das violências mais sofridas pelas mulheres, trabalhadoras do PIM é a utilização de estereótipos para colocar em xeque a capacidade e a moral dessas mulheres com forma de negar a elas condições de trabalho equivalentes ao dos homens. A opressão específica e particular é a depreciação de sua imagem diante da sociedade e a criação e manutenção de um sistema de valores que exige que ela viva cotidianamente com essa violência.

A mulher, até quando consegue ocupar lugares hierárquicos mais altos, está constantemente sendo vigiada por olhares jocosos. Ela tem que provar continuamente que mereceu aquele lugar. No âmbito profissional, precisa mostrar que tem competência para ocupar o cargo; ao passo que no âmbito moral, não pode estar ali por ter se envolvido sexualmente com uma chefia superior (LIMA, 2009).

0 que tem sido feito para mudar essa situação? No PIM, as lutas do operariado são bastante recentes. 0 Distrito Industrial nasceu em plena ditadura militar, período em que a repressão desestruturou sindicatos e organizações reivindicatórias. Nos primeiros anos da Zona Franca de Manaus, o sindicato existente era pouco atuante. Em 1982, quando uma crise econômica reduziu cerca de $50 \%$ da força de trabalho nenhum tipo de manifestação ou paralisação foi realizada.

A primeira greve realizada em Manaus foi em agosto de 1985, comandada pela Central Única dos Trabalhadores (CUT) e reivindicava aumentos salariais. Embora as reivindicações não tenham sido concedidas pelas empresas e pelo Tribunal Regional do Trabalho (TRT), o movimento foi um marco. Ele representou o início de sucessivos movimentos trabalhistas que ocorreram na segunda metade da década de 1980.

No que se refere à participação de mulheres nos sindicatos de trabalhadores do PIM é invisível. Isso não quer dizer passividade política, talvez seja o reflexo de uma estrutura sindical androcêntrica e machista que torna invisível a luta feminina no PIM.

O que interessa mencionar é que a participação das mulheres operárias foi imperativa para o suces- so dessas greves. Além de comporem a maior parte do comando de greve, elas lideraram os movimentos. Embora seu papel imprescindível não tenha tido o seu devido reconhecimento no sindicato, na mídia e nos partidos, foi a partir da luta trabalhista que as amazonenses começaram a se organizar em grupos para lutar por direitos especificamente femininos e conquistarem o seu protagonismo e autonomia.

Os movimentos feministas em Manaus pouco conseguiram solucionar as dificuldades que mulheres, cotidianamente, estão expostas, mas serviram para dar visibilidade aos problemas que elas vivenciam. Em consideração às condições femininas no PIM, atualmente, testes de gravidez não são exigidos em processos de seleção, assim como a participação em programas de controle de natalidade é voluntária. A criação da Delegacia de Crimes Contra Mulher foi uma das maiores conquistas alcançadas pelos movimentos de mulheres em Manaus. Inaugurada em 7 de julho de 1987, foi uma das primeiras do Brasil.

\section{APONTAMENTOS E CONSIDERAÇÕES FINAIS}

O objetivo desta pesquisa foi realizar um panorama das condições femininas no Amazonas em três períodos: colonial, era da borracha e era da Zona Franca de Manaus. A relação entre a história do Amazonas e as condições femininas das amazônidas nos permitiu entender o corpo da mulher como um dos instrumentos utilizados na constituição da identidade amazonense, corroborando com Scott (1990) quanto ao entendimento de que o gênero é uma categoria útil para compreensão e análise histórica.

Neste percurso, entende-se que o uso do corpo da mulher atingiu lugar de destaque, embora a mulher tenha sido, nos três períodos estudados, secundarizada. Esta análise convergiu com aquelas retratadas nos estudos de gênero presentes na literatura, em que é possível identificar afirmações quanto à atitude estratégica de organizar e esquadrinhar a relação entre mulheres e homens, mantendo significativa assimetrias entre eles. 
A cultura indígena, especialmente os comportamentos sexuais das índias, foi utilizada para endossar a política de dominação territorial. Diferente do discurso ocidental dominante que, segundo Elias (1990), aproxima as noções de 'natureza e barbárie', argumenta-se que no Amazonas as características femininas consideradas primitivas foram tramadas para conferir à floresta uma atmosfera de civilização convidativa. Essa especificidade nos remete às problematizações de De Lauretis (1987), ao afirmar que a diferenciação entre o masculino e o feminino é responsável por construir a realidade, ao invés de espelhá-la. Neste sentido, conclui-se que a construção da realidade colonial da região do Amazonas foi amplamente perpassada pelas distinções e papéis de gênero, evidenciando particularidades no uso da moral para educação dos corpos das indígenas e dos colonizadores.

Porém, a norma da permissividade sexual do período colonial não se manteve na era da borracha. As índias e as caboclas foram sujeitadas às mulheres que reproduziam características do padrão europeu, cabendo às primeiras os espaços toleráveis, mas não apreciáveis. Tais transformações fortalecem nosso segundo argumento de que as mudanças temporais das funções de gênero serviram para ordenar as relações sociais alteradas pelo boom de riquezas oriundas da produção da borracha. Segundo pontua Scott (1990), os papéis sexuais e o simbolismo sexual são ferramentas políticas para alcançar o ordenamento social, ajudando a elucidar a relação de dominação entre grupos classificatórios.

Indica-se, seguindo a discussão, que a Amazônia, além de ter sido assentada em uma cultura tradicional e patriarcal, teve como base uma ordem social nada democrática: o patrimonialismo. Favoritismo, machismo, nepotismo e clientelismo dificultaram a inserção e o crescimento das mulheres no mercado de trabalho da Zona Franca de Manaus. Conforme apontado, os direitos reprodutivos serviram como elemento de fomento às boas condições de funcionamento da zona industrial, tendo a sexualidade feminina (em detrimento da masculina) se mantido como objeto de controle e vigilância.

O modus operandis de controle da mulher pelas vias da sexualidade e reprodução fortaleceu a lógica persuasiva específica. Nosso terceiro argumento é que ao es- quadrinhar as ações da mulher trabalhadora, pagar-lhe salário mais baixo e exigir prova constante de sua conduta moral, a Zona Franca de Manaus (e posteriormente o Polo Industrial de Manaus) limitou o contato da mulher com uma maior possibilidade de exercício de poder, tornando-a secundária no processo de desenvolvimento. Segundo Ortner (1979) tornar a mulher classe secundária é fortalecer o argumento de que ela é um ser inferior. Esse apontamento permite refletir sobre as dificuldades das próprias mulheres trabalhadoras de tornar visível os atos frutos de uma consciência política e crítica.

Hoje, entre os grupos de mulheres mais atuantes destacam-se o Fórum Permanente de Mulheres de Manaus; o Conselho Municipal dos Direitos da Mulher; a Pastoral da Mulher Operária; o Consulado da Mulher de Manaus; 0 Movimento de Humanização do Parto e Nascimento; Movimento de Mulheres por Moradia Orquídea; Movimento das Mulheres Negras da Floresta; o grupo Maria em Ação, da Universidade Federal do Amazonas (UFAM); o Instituto Mana; e o grupo Feminismo em Manaus.

Infelizmente, nos meios de comunicação, a atuação desses grupos foi quase inexistente, em geral, só apareciam no mês de março, durante as comemorações do Dia Internacional da Mulher, ou em outro evento de caráter comemorativo. Atualmente, com as pautas emergentes sobre empoderamento feminino, combate a violência no parto e assédio sexual contra mulheres, já é possível identificar, mesmo que incipiente, as ações protagonizadas por essas mulheres nos meios de comunicação do Amazonas.

Para finalizar, registramos o reconhecimento da participação ativa das mulheres ao longo da história do Amazonas, com preponderância no "descobrimento", na colonização, no povoamento e no desenvolvimento das atividades produtivas/industriais. Seu papel nas relações familiares, na educação, na industrialização e nas lutas pelos delineamentos da sociedade amazonense parece-nos notório. Desnaturalizar papéis de gênero e problematizar as práticas sexistas e etnocêntricas, características das condições femininas que se iniciaram nos primeiros anos de colonização e que estão presentes até hoje, são atos fundamentais para o fortalecimento do movimento de mulheres da região. 


\section{REFERÊNCIAS}

ADAMS, Cristina; MURRIETA, Rui; NEVES, Walter. Introdução: As sociedades caboclas amazônicas - modernidade e invisibilidade. In: ADAMS, C.; MURRIETA, R.; NEVES, W. (Org.). As sociedades caboclas amazônicas: modernidade e invisibilidade. São Paulo: Annablume, 2008.

BARBOSA, lerecê. Chão de fábrica: ser mulher operária no Pólo Industrial de Manaus. Manaus: Valer, 2007.

BOYER, Véronique. 0 pajé e o caboclo: de homem a entidade. Mana [on-line], v.5, n.1, p.29-56, 1999. http://dx.doi.org/10.1590/S010493131999000100002

CANCELA, Cristina Donza. Destino cor-de-rosa, tensão e escolhas: os significados do casamento em uma capital amazônica (Belém, 1870-1920).

Cadernos Pagu, Santa Catarina, n.30, v.1, 2008.

COSTA, Heloísa Lara Campo; et al. Políticas públicas, desigualdades sociais e crianças no Amazonas. Série pobreza e meio ambiente na Amazônia. Belém: UNAMAZ, UFPA, FUA, 1993.

COSTA, Heloísa Lara Campos. A respeito da lógica do poder: o controle sobre o trabalho feminino em duas empresas de Manaus. Ciências humanas: revista da Universidade do Amazonas, Manaus: v.8, n.1/2, p.1-33, 2000.

DE LAURETIS, Teresa. Technologies of Gender. Blomington: Indiana University

Press, 1987 (p.ix-xi; 1-30).

DINIZ, Gláucia Ribeiro Starling. Condição Feminina: fator de Risco para a Saúde Mental? In: PAZ, M.G.T.; TAMAYO, A. (Org). Escola, Saúde e Trabalho: estudos Psicológicos. Brasília: Universidade de Brasília, 1999. p.181-197.
ELIAS, N. 0 processo civilizador. Rio de Janeiro, Zahar: 1990.

FOUCAULT, M. História da Sexualidade: a vontade de saber. Rio de Janeiro/São Paulo: Paz na Terra, 2015.

GUZMÁN, Décio de Alencar. A colonização nas Amazônias: guerras, comércio e escravidão nos séculos XVII e XVIII. Revista Estudos Amazônicos, Belém, v.3, n.2, p.103-139, 2008.

HARRIS, Mark. Presente ambivalente: uma maneira amazônica de estar no tempo. In: ADAMS, C.; MURRIETA, R.; NEVES, W. (Org.). As sociedades caboclas amazônicas: modernidade e invisibilidade. São Paulo: Annablume, 2008.

IBGE - INSTITUTO BRASILEIRO DE GEOGRAFIA E ESTATÍSTICA. Sinopse do senso demográfico de 2010. Rio de Janeiro, 2011.

\section{LIMA, Vivian Silva. Produzidas no Polo Industrial de}

Manaus: experiências de mulheres trabalhadoras. 2009. 189f. Dissertação (Mestrado em Psicologia Clínica e Cultura) - Instituto de Psicologia, Universidade de Brasília - UnB, Brasília.

NUGENT, Stephen. Utopias e distopias na paisagem social amazônica. In: ADAMS, C.; MURRIETA, R.; NEVES, W. (Org.). As sociedades caboclas amazônicas: modernidade e invisibilidade. São Paulo: Annablume, 2008, p.33-44.

OLIVEIRA, José Aldemir. Tempo e espaço urbano na Amazônia no período da borracha. Revista electrónica de geografía y ciencias sociales. v.10, n.218, Espanha: Universidad de Barcelona, 2006.

ORTNER, Sherry. Está a mulher para o homem assim como a natureza para a cultura? In: ROSALDO, Michelle; LAMPHERE, Louise. A mulher, a cultura, a sociedade. Rio de Janeiro: Paz e Terra, 1979, p.96-120. 
ORUM, Thomas. The Women of the oper door: jews in the belle époque amazonian demimonde, 1890-1920. An interdisciplinary journal of Jewish studies, Ashland, v.19, n.3, 2001.

RAYMUNDO, Letícia de Oliveira. 0 estado do GrãoPará e Maranhão na nova ordem política pombalina: a Companhia Geral do Grão-Pará e Maranhão e o Diretório dos Índios (1755-1757). Informes de Pesquisa: Almanack Brasiliense, São Paulo, n.3, p.124-134, 2006.

SANTOS, Luiz Fernando de Souza. Amazônia: das ideias de paraíso às ideias de ecossistema. In: BASTOS, E.; PINTO, R. (Org.). Vozes da Amazônia: Investigação sobre o pensamento social brasileiro. Manaus: Edua, 2007. p.377-417.
SCOTT, Joan. Gênero: uma categoria útil para análise histórica. Revista Educação e Realidade. Porto Alegre, v.16, n.2, p.5-22, jul./dez. 1990.

SPINDEL, Cheywa Rojza. Formação de um novo proletariado: as operárias do Distrito Industrial de Manaus. Revista brasileira de estudos de população, São Paulo: v.4, n.2, p.1-37, 1987.

TORRES, Iraildes Caldas. A visibilidade do trabalho das mulheres Ticunas da Amazônia. Estudos Feministas, Florianópolis: v.15, n.2, p.469-475, 2007.

TORRES, Iraildes Caldas. As novas amazônidas. Manaus: Edua, 2005.

\author{
1 Psicóloga; Mestre em Psicologia pela Universidade de Brasília; \\ Professora da Escola Superior de Ciências da Saúde da Universidade do \\ Estado do Amazonas; Pesquisadora do Núcleo de Estudos Psicossociais \\ sobre Direitos Humanos e Saúde. E-mail: vivislima@hotmail.com \\ 2 Graduada em Psicologia (Graus de Bacharel e Psicóloga) pela \\ Universidade Federal de Minas Gerais (1981); Especialista em Saúde \\ Coletiva pela Escola de Saúde de Minas Gerais - UFMG/FIOCRUZ \\ (1983); Mestre (1990) e Doutora (1993) no Marriage And Family \\ Therapy Program - United States International University, hoje Alliant \\ International University, San Diego, California, EUA; Professora \\ Adjunto da Universidade de Brasília, lotada no Departamento de \\ Psicologia Clínica, Instituto de Psicologia; Docente permanente do \\ Programa de Pós-Graduação em Psicologia Clínica e Cultura - PPG \\ PsiCC/PCL/IP/UnB. E-mail: andre07machado@hotmail.com \\ 3 Psicólogo; Mestre em Psicologia pela Universidade Federal do \\ Amazonas; Doutor em Saúde Coletiva pela Universidade do Estado \\ do Rio de Janeiro; Pesquisador do grupo de pesquisa: Núcleo de \\ Estudos Psicossociais sobre Direitos Humanos e Saúde. E-mail: \\ andre07machado@hotmail.com \\ 4 Psicóloga; Mestre em Psicologia pela Universidade Federal do Rio \\ Grande do Norte; Doutora em Saúde Coletiva pela Universidade do \\ Estado do Rio de Janeiro; Pesquisadora do grupo de pesquisa: Núcleo \\ de Estudos Psicossociais sobre Direitos Humanos e Saúde. E-mail: \\ mtherense@gmail.com \\ 5 Professora da Escola Superior de Ciências da Saúde da Universidade \\ do Estado do Amazona - UEA; Psicóloga; Mestre em psicologia pela \\ Universidade Federal do Espírito Santo; Pesquisadora do grupo de \\ pesquisa: Núcleo de Estudos Psicossociais sobre Direitos Humanos e \\ Saúde. E-mail: gizadcm@gmail.com
}

